\title{
OFFSHORE SAND DISCHARGE CAUSED BY CONSTRUCTING COASTAL STRUCTURES ON A STEEP COAST WITH A LARGE SHORELINE CURVATURE
}

\author{
Shiho Miyahara' ${ }^{1}$ Takaaki Uda², Masumi Serizawa' and Shusuke Watanabe
}

\begin{abstract}
A groin or a detached breakwater was installed at a cuspate foreland formed on a coast with an abrupt change in coastline orientation and the effect of obstructing longshore sand transport was investigated. The results of the experiment were reproduced using the BG model (a 3-D model for predicting beach changes based on Bagnold's concept). The beach changes around the structures installed at the cuspate foreland were successfully predicted and the experimental and numerical results were in good agreement. The differences between the effects of the groin and detached breakwater in controlling longshore sand transport and the offshore sand discharge caused by constructing such coastal structures on a steep coast were successfully explained.
\end{abstract}

Keywords: beach changes; large shoreline curvature; submarine canyon; BG model; groin; detached breakwater

\section{INTRODUCTION}

On a coast where steep submarine canyons extend very close to the shoreline, offshore sand discharge may occur through the steep slope around the canyon head toward the deep ocean, resulting in a significant loss of littoral sand. On such a coast, marked beach erosion may occur because beaches are directly exposed to ocean waves; therefore, shore protection facilities have often been constructed as a measure against beach erosion in such an area. The construction of such structures, however, may cause further shoreline instability by accelerating offshore sand transport. An example can be found on the Shimoniikawa coast with a steep slope facing the Sea of Japan (Yamada et al., 2010). Although the construction of a groin or a detached breakwater on such a steep coast is considered to increase offshore sand discharge, the prediction of beach changes on such a coast is difficult using an ordinary three-dimensional (3-D) predictive model, except when part of the seabed is assumed to be solid (Yamada et al., 2010). We have developed the BG model (a 3-D model for predicting beach changes based on Bagnold's concept) (Serizawa and Uda, 2011), and its applicability has been validated through various applications. In this study, this model was applied to the prediction of beach changes around a groin and a detached breakwater placed on a steep coast with a large shoreline curvature. For the validation, we used the results of a movable-bed experiment (Uda et al., 1992), and the effect of these coastal structures on a steep coast was numerically investigated.

\section{MOVABLE-BED EXPERIMENT}

Uda et al. (1992) carried out a movable-bed experiment to investigate beach changes around a groin and a detached breakwater placed on a steep coast with a large shoreline curvature using a plane wave tank of $16 \mathrm{~m}$ width and $21 \mathrm{~m}$ length. The model beach used was made of sand with $d_{50}=0.28$ $\mathrm{mm}$. A sandy beach was established as the source of sand in the right half of the plane basin and conditions were set up such that leftward longshore sand transport develops. The offshore bed in the left half of the wave basin was constructed with a steep slope of $1 / 5$. The wave angle between the direction normal to the initial shoreline and the wave direction was set to be $20^{\circ}$ so that longshore sand transport develops. The crown height of the flat sandy beach, from which sand was supplied downcoast, was set to be $10 \mathrm{~cm}$ above the still water level. Regular waves with a height $H_{0}{ }^{\prime}=4.6 \mathrm{~cm}$ and $T=1.27$ $\mathrm{s}$ were generated for $8 \mathrm{hr}$.

Figures 1(a) and 1(b) show the bathymetries at the initial stage and after the 8-hr wave generation, respectively, obtained by the movable-bed experiment using a plane wave tank. The arrows in Fig. 1(a) show the breaking point (the tip of the arrows), the breaker height (the length of the arrows), and the wave direction at the breaking point (the direction of the arrows) measured immediately after the wave generation. Because of the large water depth in the sand deposition zone, sand was deposited to form a steep slope and a cuspate foreland was formed around the area with a sudden change in coastline after $8 \mathrm{hr}$. Then, a groin was installed at $X=8 \mathrm{~m}$ in Fig. 1(b) after the wave generation of $8 \mathrm{hr}$, and the subsequent beach changes were measured for $8 \mathrm{hr}$. Figure 1(c) shows the bathymetry after the wave generation of $8 \mathrm{hr}$. Because the groin obstructed leftward longshore sand transport, the contours advanced upcoast of the groin, whereas downcoast shoreline retreated forming a gentle wave-cut slope

\footnotetext{
${ }^{1}$ Coastal Engineering Laboratory Co., Ltd., 1-22-301 Wakaba, Shinjuku, Tokyo 160-0011, Japan

${ }^{2}$ Public Works Research Center, 1-6-4 Taito, Taito, Tokyo 110-0016, Japan
} 
in the offshore zone. Figure 2 shows the shoreline changes after the construction of a groin. Shoreline discontinuity was observed at the groin. In particular, the downcoast shoreline, which had a convex shape under the initial conditions, significantly retreated, resulting in the formation of a concave shoreline.

(a) initial stage

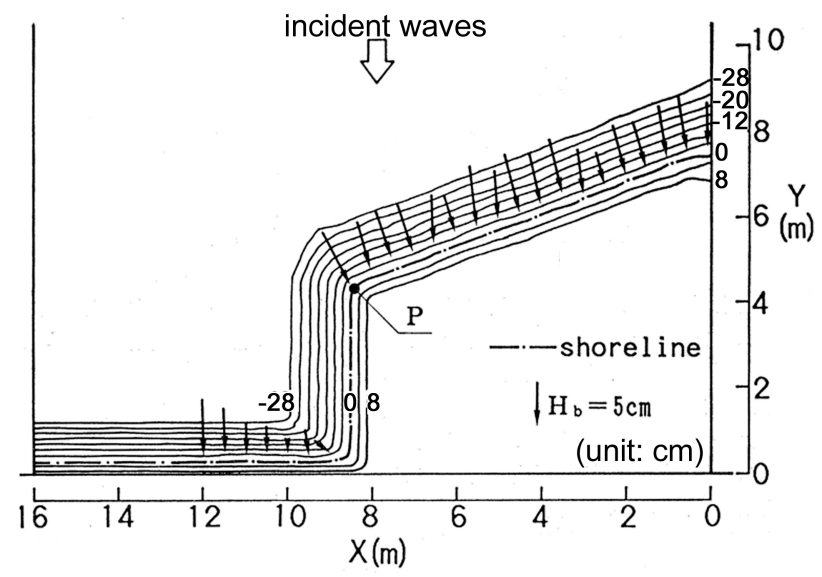

(b) $\mathrm{t}=8 \mathrm{hr}$

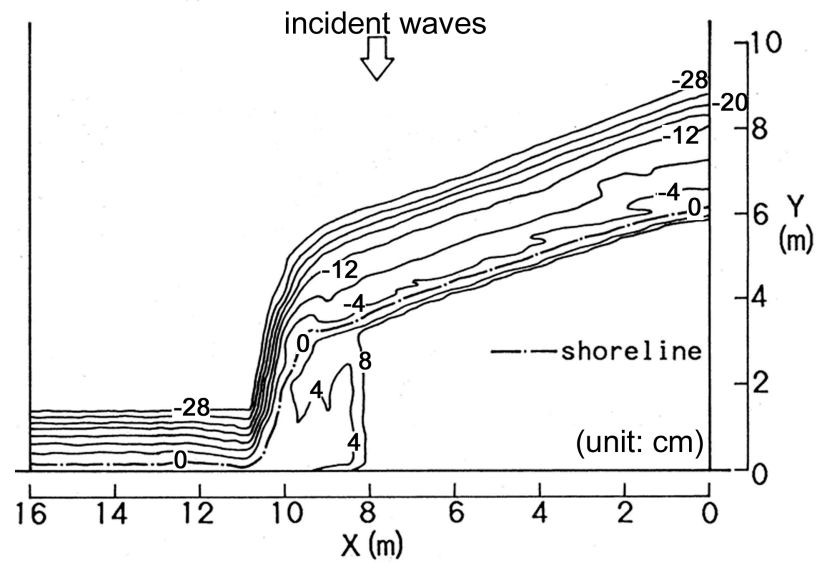

(c) $\mathrm{t}=8 \mathrm{hr}$ after installation of a groin

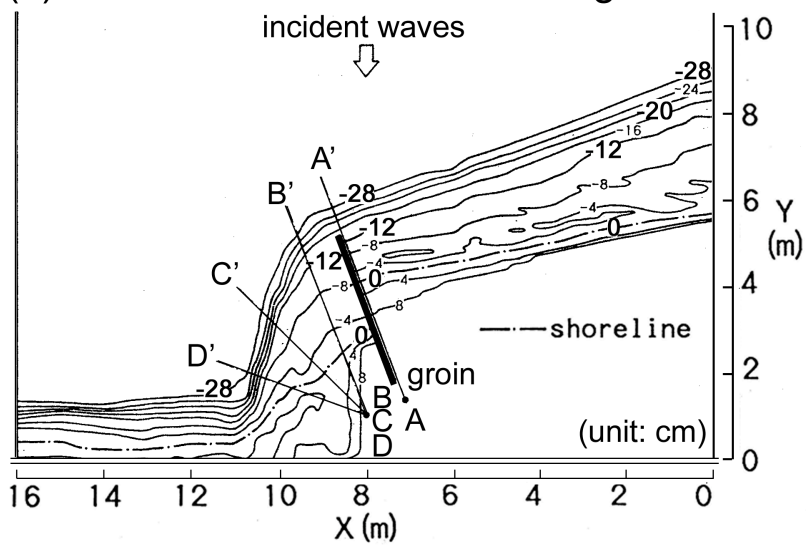

Figure 1. Topographic changes around a groin placed on a steep coast with a large shoreline curvature (experiment). 


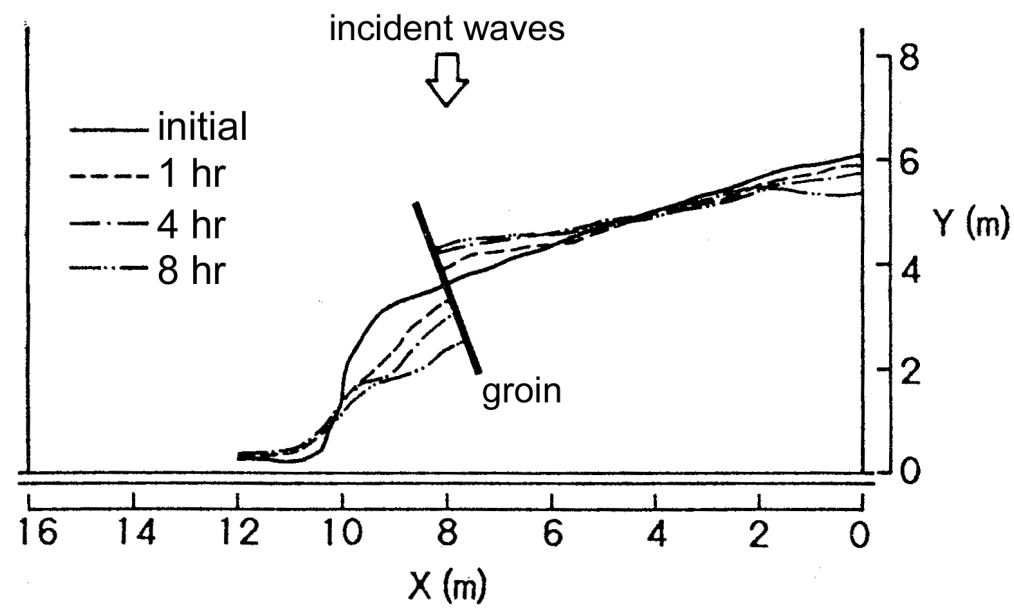

Figure 2. Shoreline changes around a groin (experiment).

\section{NUMERICAL MODEL}

The BG model proposed by Serizawa and Uda (2011) with an additional term from Ozasa and Brampton (1980) was used in the numerical simulation. The fundamental equation is given by

$$
\begin{gathered}
\vec{q}=C_{0} \frac{P}{\tan \beta_{\mathrm{c}}}\left\{\begin{array}{c}
K_{n}\left(\tan \beta_{c} \overrightarrow{e_{w}}-|\cos \alpha| \overrightarrow{\nabla Z}\right) \\
+\left\{\left(K_{s}-K_{n}\right) \sin \alpha-\frac{K_{2}}{\tan \bar{\beta}} \frac{\partial H}{\partial s}\right\} \tan \beta \overrightarrow{e_{s}}
\end{array}\right\} \\
\left(-h_{c} \leq Z \leq h_{R}\right) \\
P=\rho u_{m}^{3} \\
u_{m}=\frac{H}{2} \sqrt{\frac{g}{h}}
\end{gathered}
$$

where $\vec{q}=\left(q_{x}, q_{y}\right)$ is the net sand transport flux, $Z(x, y, t)$ is the elevation, $n$ and $s$ are the local coordinates taken along the directions normal (shoreward) and parallel to the contour lines, respectively, $\overrightarrow{\nabla Z}=(\partial Z / \partial x, \partial Z / \partial y)$ is the slope vector, $\overrightarrow{e_{w}}$ is the unit vector of the wave direction, $\overrightarrow{e_{s}}$ is the unit vector parallel to the contour lines, $\alpha$ is the angle between the wave direction and the direction normal to the contour lines, $\tan \beta=|\overrightarrow{\nabla Z}|$ is the seabed slope, $\tan \beta_{c}$ is the equilibrium slope, $\tan \beta \overrightarrow{e_{s}}=(-\partial Z / \partial y, \partial Z / \partial x), K_{s}$ and $K_{n}$ are the coefficients of longshore and cross-shore sand transport, respectively, $K_{2}$ is the coefficient of the term given by Ozasa and Brampton (1980), $\partial H / \partial s=\overrightarrow{e_{s}} \cdot \overrightarrow{\nabla H}$ is the longshore gradient of the wave height $H$ measured parallel to the contour lines, $\operatorname{and} \tan \bar{\beta}$ is a characteristic slope of the breaker zone. In addition, $C_{0}$ is the coefficient transforming the immersed weight expression into the volumetric expression $\left(C_{0}=1 /\left\{\left(\rho_{s}-\rho\right) g(1-p)\right\}\right.$, where $\rho$ is the density of seawater, $\rho_{s}$ is the specific gravity of sand particles, $p$ is the porosity of sand, and $g$ is the acceleration of gravity), $u_{m}$ is the amplitude of the seabed velocity due to the orbital motion of waves, $h_{c}$ is the depth of closure, and $h_{R}$ is the berm height.

Because recurrent feedback calculations are necessary in response to topographic changes, the energy balance equation method (Mase, 2001) was used in calculating the wave field so that the calculation load is small. In the calculation of the wave field on land, the imaginary depth $h^{\prime}$ was considered to be given by Eq. (4), between the minimum depth $h_{0}$ and the berm height $h_{R}$.

$$
h^{\prime}=\left(\frac{h_{R}-Z}{h_{R}+h_{0}}\right)^{r} h_{0} \quad(r=1) \quad\left(-h_{0} \leq Z \leq h_{R}\right)
$$

In addition, at locations higher than the berm height, the wave energy was set to be 0 . The wave field was calculated every 10 steps of the calculation of topographic changes. In the numerical simulation of 
beach changes, the sand transport and continuity equations were solved on the $x-y$ plane by the explicit finite-difference method.

\section{CALCULATION CONDITIONS}

For convenience, the space scale in the calculation was set to be 100 -fold that in the experiment, and the calculated results were then reduced to a scale of 1/100. Given the same initial topography and wave conditions as those of the experiment (regular waves with $H_{I}=4.6 \mathrm{~m}$ and $T=12.7 \mathrm{~s}$, incident to the model beach with an angle of $20^{\circ}$ ), the beach changes after $80 \mathrm{hr}$ of wave generation were predicted. The depth of closure was given by $h_{\mathrm{c}}=2.5 H$ ( $H$ : wave height at a local point). The berm height was assumed to be $5 \mathrm{~m}$, and the equilibrium slope and the angle of the repose slope were $1 / 5$ and $1 / 2$, respectively, on the basis of the experimental results. The calculation domain was divided by $\Delta x=\Delta y=$ $20 \mathrm{~m}$ intervals in the cross-shore and longshore directions, and calculation up to $80 \mathrm{hr}\left(8 \times 10^{4}\right.$ steps $)$ was carried out using the time interval of $\Delta t=1 \times 10^{-3} \mathrm{hr}$. Table 1 shows the calculation conditions. The regular-wave conditions in the experiment were replaced with irregular-wave conditions, and wave field calculation was carried out every 10 steps of the calculation of topographic changes.

\begin{tabular}{|c|c|}
\hline Wave conditions & $\begin{array}{l}\text { Incident waves: } H_{l}=4.6 \mathrm{~m}(4.6 \mathrm{~cm}), T=12.7 \mathrm{~s}(1.27 \mathrm{~s}) \text {, wave direction } \theta_{l}=20^{\circ} \\
\text { relative to normal to initial shoreline }\end{array}$ \\
\hline Berm height & $h_{R}=5 \mathrm{~m}(5 \mathrm{~cm})$ \\
\hline Depth of closure & $h_{c}=2.5 H(H:$ wave height $)$ \\
\hline Equilibrium slope & $\tan \beta_{c}=1 / 5$ \\
\hline Angle of repose slope & $\tan \beta_{g}=1 / 2$ \\
\hline Coefficients of sand transport & $\begin{array}{l}\text { Coefficient of longshore sand transport } K_{s}=0.045 \\
\text { Coefficient of Ozasa and Brampton }(1980) \text { term } K_{2}=1.62 K_{s} \\
\text { Coefficient of cross-shore sand transport } K_{n}=0.1 K_{s}\end{array}$ \\
\hline Mesh size & $\Delta x=\Delta y=20 \mathrm{~m}$ \\
\hline Time interval & $\Delta t=0.001 \mathrm{hr}(0.0001 \mathrm{hr})$ \\
\hline Duration of calculation & $80 \mathrm{hr}\left(8 \times 10^{4}\right.$ steps $)(8 \mathrm{hr})$ \\
\hline Boundary conditions & Shoreward and landward ends: $q_{x}=0$, right and left boundaries: $q_{y}=0$ \\
\hline Calculation of wave field & $\begin{array}{l}\text { Energy balance equation (Mase, 2001) } \\
\text { - Term of wave dissipation due to wave breaking: Dally et al. (1984) model } \\
\text {-Wave spectrum of incident waves: directional wave spectrum density obtained } \\
\text { by Goda (1985) } \\
\text { - Total number of frequency components } N_{F}=1 \text { and number of directional } \\
\text { subdivisions } N_{\theta}=8 \\
\text {-Directional spreading parameter } S_{\max }=75 \\
\text { - Coefficient of wave breaking } K=0.17 \text { and } \Gamma=0.3 \\
\text {-Imaginary depth between minimum depth } h_{0} \text { and berm height } h_{R} \\
\qquad h_{0}=2 \mathrm{~m}(2 \mathrm{~cm}) \\
\text {-Wave energy }=0 \text { where } Z \geq h_{R} \\
\text { - Lower limit of } h \text { in terms of wave decay due to breaking } \Phi: 0.7 \mathrm{~m}(0.7 \mathrm{~cm})\end{array}$ \\
\hline Remarks & $\begin{array}{l}\text { Numbers in parentheses show experimental values. The space and time scales } \\
\text { in the calculation are } 100 \text { - and } 10 \text {-fold those in the experiment, respectively. }\end{array}$ \\
\hline
\end{tabular}

\section{RESULTS OF NUMERICAL SIMULATION}

\section{Effect of groin}

Serizawa and Uda (2011) have applied the BG model to the prediction of beach changes around an area with a sudden change in the coastline on a steep coast, and showed the predicted results after an 8hr wave generation. Figure 3 shows the results of the calculation of the development of a cuspate foreland on a steep coast 0,8 and $16 \mathrm{hr}$ after the wave generation. The contour lines that extended parallel to each other at the initial stage around the area with a sudden change in the coastline rapidly changed over time, causing sand deposition into the deep zone. A cuspate foreland was formed up to 8 $\mathrm{hr}$ around the area with a sudden change in the coastline via sand spit formation, as shown by Serizawa and Uda (2011). After $16 \mathrm{hr}$, a smoothly curved shoreline of the cuspate foreland was formed owing to the successive sand deposition into the deeper zone, whereas a wave base with a gentle wave-cut slope was formed on the upcoast.

In predicting beach changes after the installation of a groin, the bathymetry after the wave generation of $8 \mathrm{hr}$, as shown in Fig. 3(b), was selected as the initial bathymetry, and the beach changes $16 \mathrm{hr}$ from the beginning of the wave generation with and without a groin were compared each other. Figures 4(a) and 4(b) show the initial bathymetry immediately after the installation of a groin at $X=8$ 
$\mathrm{m}$ on a coast with a large shoreline curvature and the predicted bathymetry after the wave generation of $8 \mathrm{hr}$, respectively, assuming that the groin is given as an impermeable solid wall. Because of the blockage of longshore sand transport by the groin, sand was deposited upcoast of the groin, and a steep slope extending from the shoreline to the offshore steep slope was formed, whereas the shoreline markedly receded downcoast of the groin, resulting in a formation of the wave-cut slope. These features well explain the experimental results shown in Fig. 1(c).

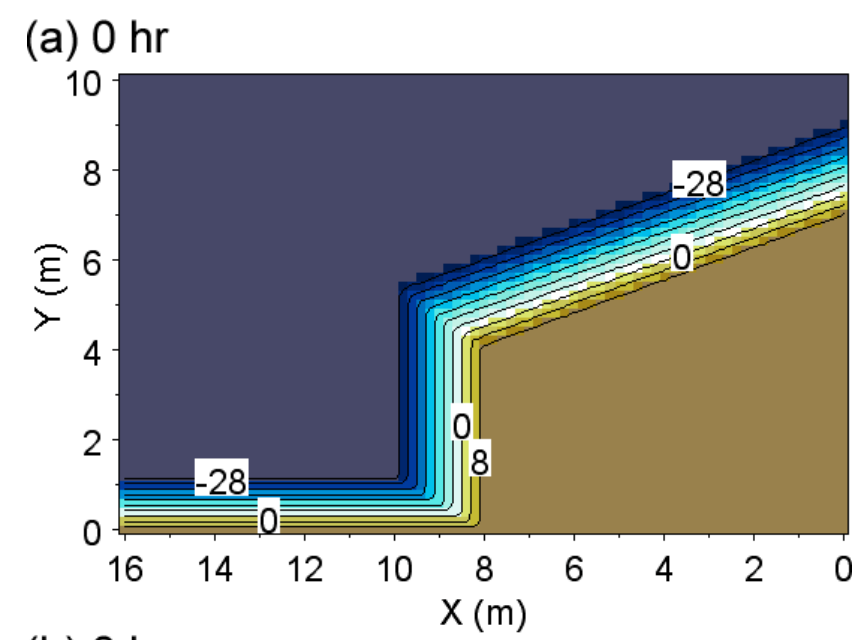

(b) $8 \mathrm{hr}$

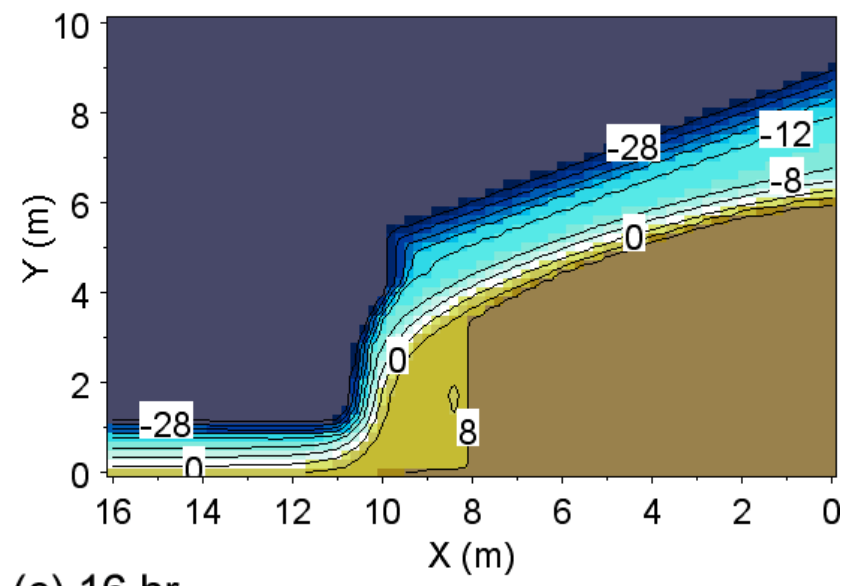

(c) $16 \mathrm{hr}$

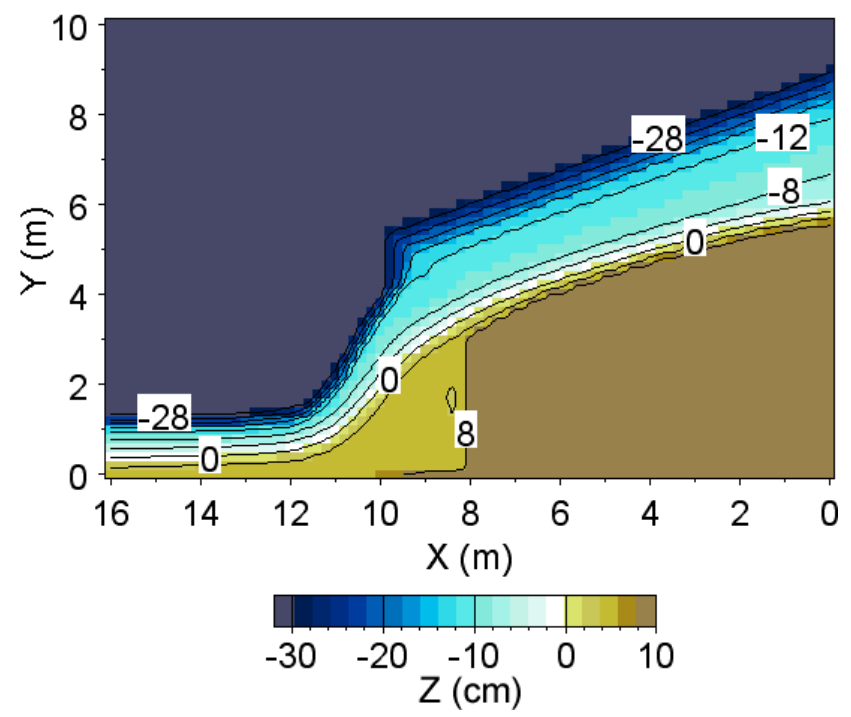

Figure 3. Predicted topographic changes on a steep coast with a large shoreline curvature. 


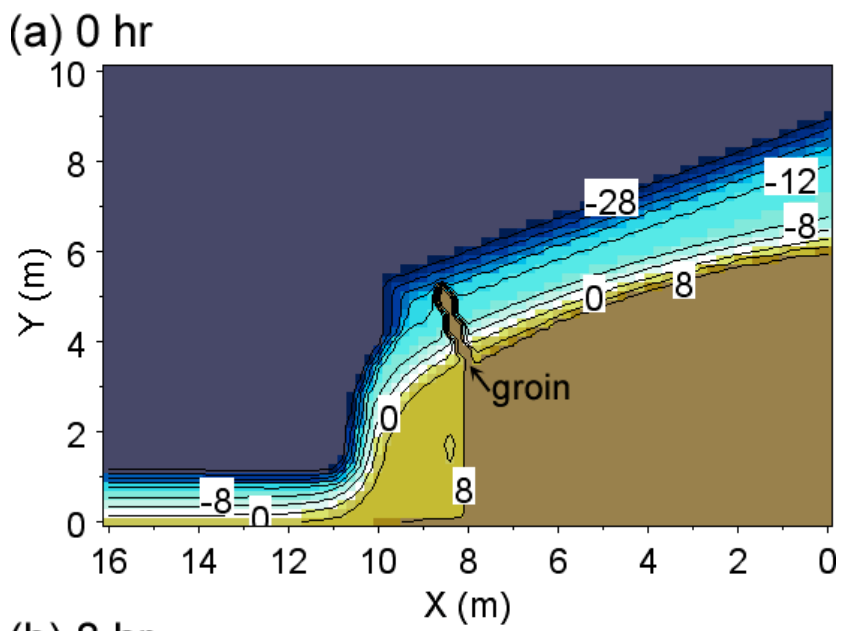

(b) $8 \mathrm{hr}$

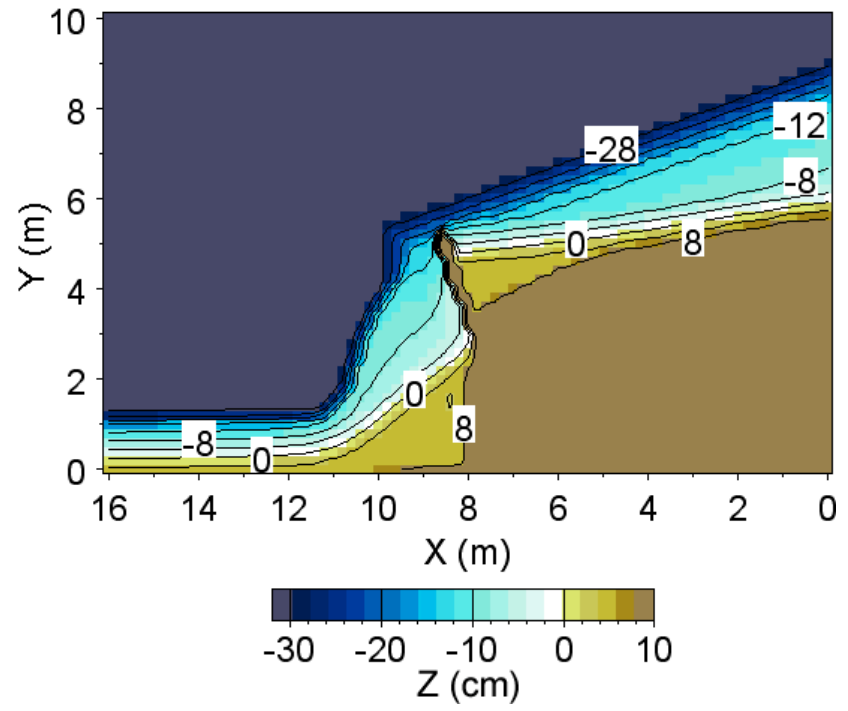

Figure 4. Predicted topographic changes around a groin placed on a steep coast with a large shoreline curvature.

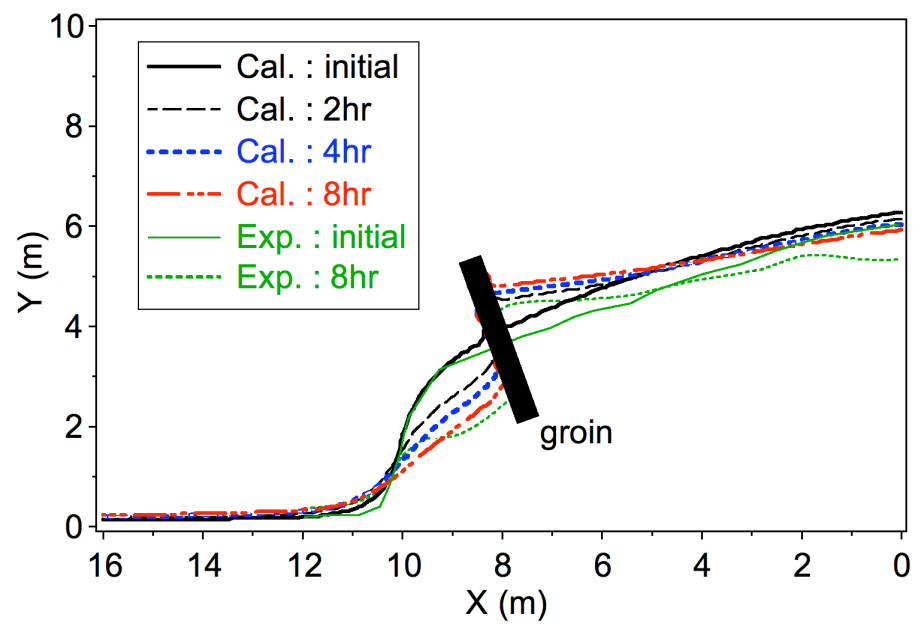

Figure 5. Shoreline changes (experiment vs. calculation). 
Figure 5 shows the predicted and measured shoreline changes at $2 \mathrm{hr}$ intervals from the start up to $8 \mathrm{hr}$. Because the calculated shoreline changes under the condition without the groin were slightly smaller than the experimental results under the same condition, there was some discrepancy between the experimental and calculated shorelines at the start of the calculation. Therefore, the shoreline configurations at the start and after $8 \mathrm{hr}$ in both experiment and numerical simulation are shown in Fig. 5 , and their individual changes were noted. The gradual shoreline advance and concave shoreline formation upcoast and downcoast of the groin, respectively, are in good agreement with the experiment and numerical simulation results.

Figure 6 shows the measured and predicted profile changes along transects A-A', B-B', C-C' and D-D', as shown in Fig. 1. Although there are some discrepancies between the measured and predicted profiles, the measured and predicted profile changes are in good agreement. In particular, the profile changes along transects B-B', C-C' and D-D' downcoast of the groin are in good agreement.
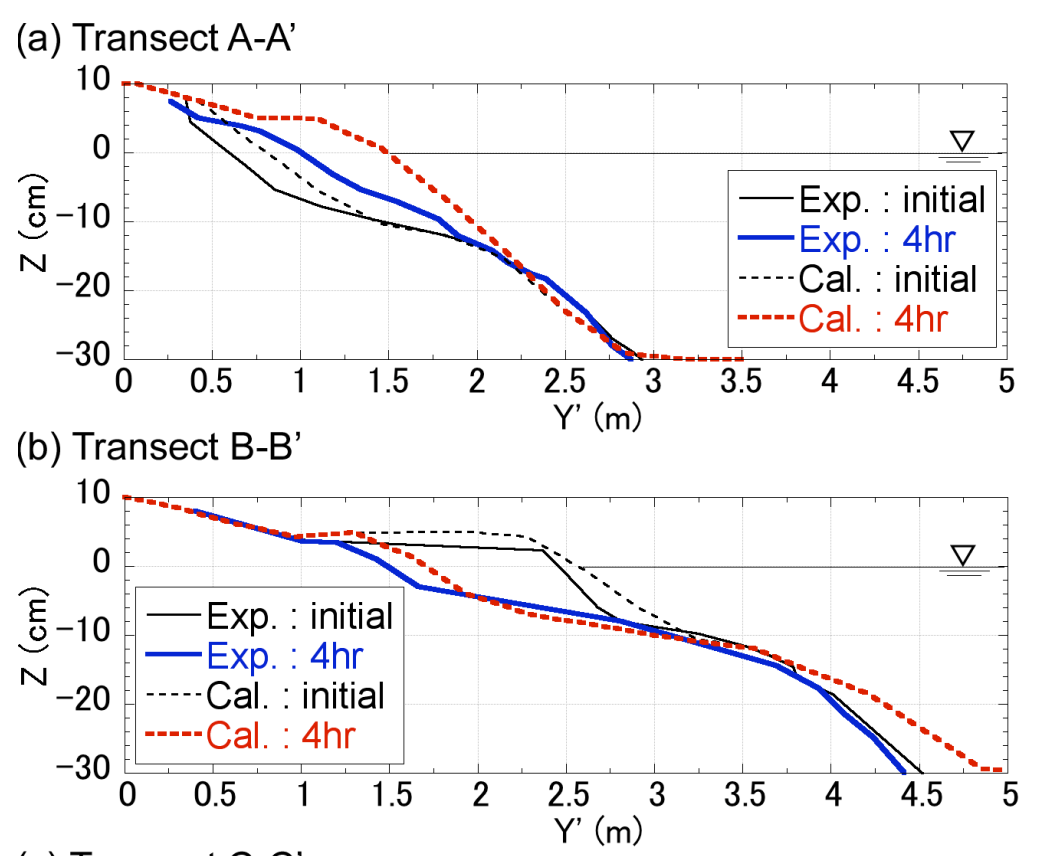

(c) Transect C-C'

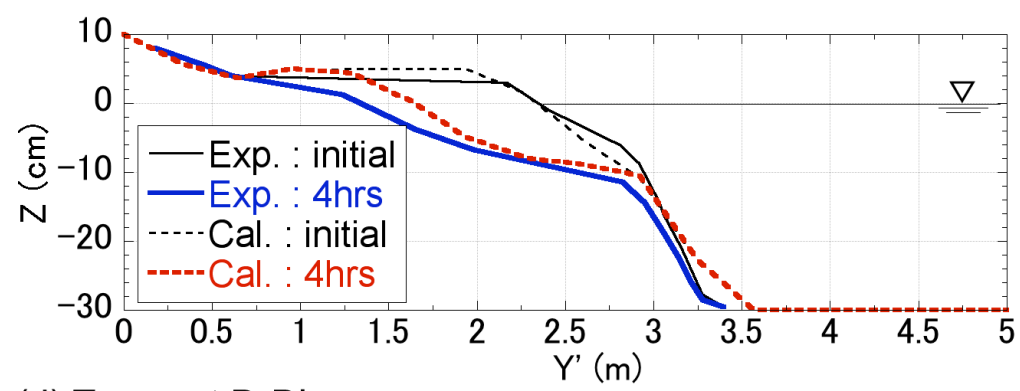

(d) Transect D-D'

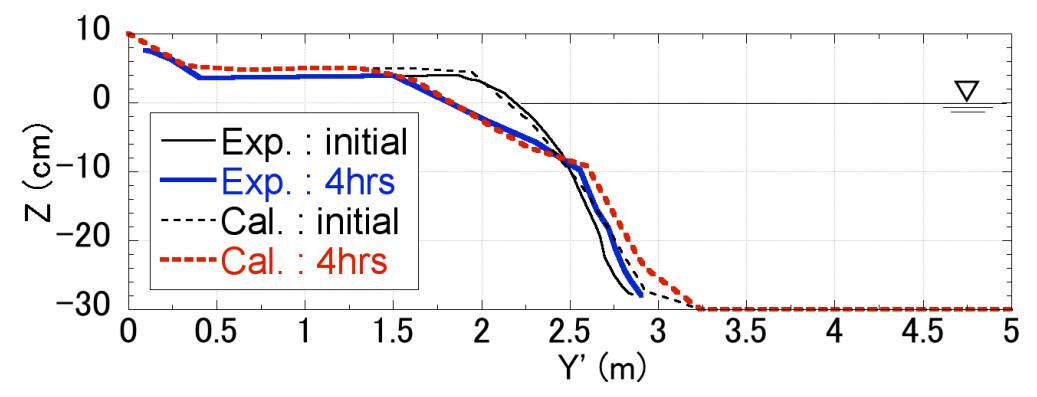

Figure 6. Changes in longitudinal profiles along transects A-A', B-B', C-C' and D-D' (experiment vs. calculation). 


\section{Effect of detached breakwater}

We predicted bathymetric changes when a detached breakwater instead of a groin was built. The detached breakwater was placed so that the center of the detached breakwater is at $X=8 \mathrm{~m}$ with a depth of $8 \mathrm{~cm}$, as shown in Fig. 7(a). Because the beach changes occurred in a zone shallower than 12 $\mathrm{cm}$ upcoast of the groin, owing to the change in the longitudinal profile along transect A-A', as shown in Fig. 6(a), the depth of the detached breakwater was determined so that almost all the sand movement in this zone can be covered.

Figure 7 shows the initial and predicted bathymetries after the wave generation of $8 \mathrm{hr}$ when a detached breakwater of a 2 m length was installed at $X=8 \mathrm{~m}$. After the installation of the detached breakwater, the shoreline smoothly connected to the detached breakwater and a steep slope was formed upcoast of the detached breakwater because of sand deposition on the updrift side of the breakwater, resulting in a decrease in the interval between the 8- and 12-cm-deep contours. In contrast, a concave contour was formed between the 4- and 8-cm-deep contours immediately downcoast of the detached breakwater. These spatial changes at intervals of the contours show that offshore sand transport occurred upcoast of the detached breakwater and landward sand transport downcoast of the detached breakwater, with longshore sand transport from the region upcoast to the region downcoast of the detached breakwater.

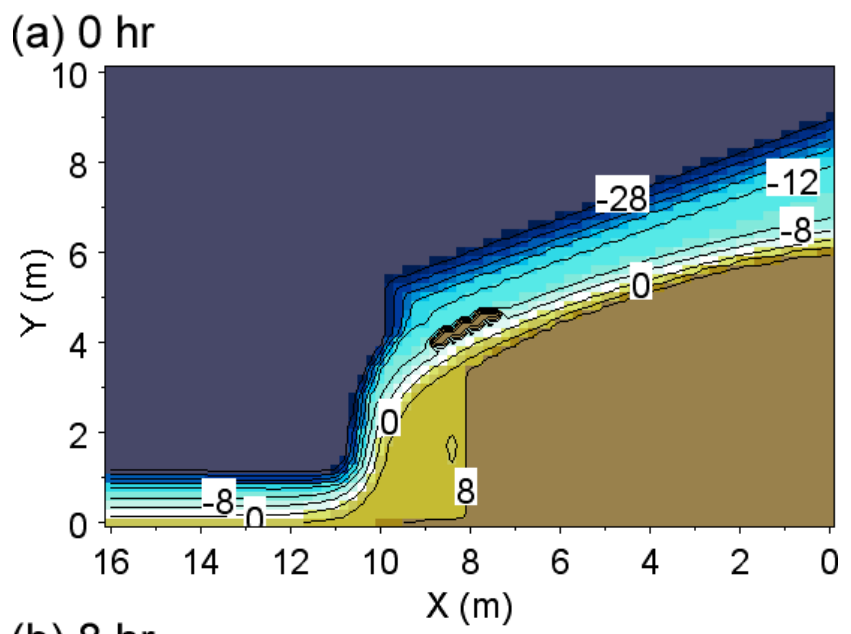

(b) $8 \mathrm{hr}$

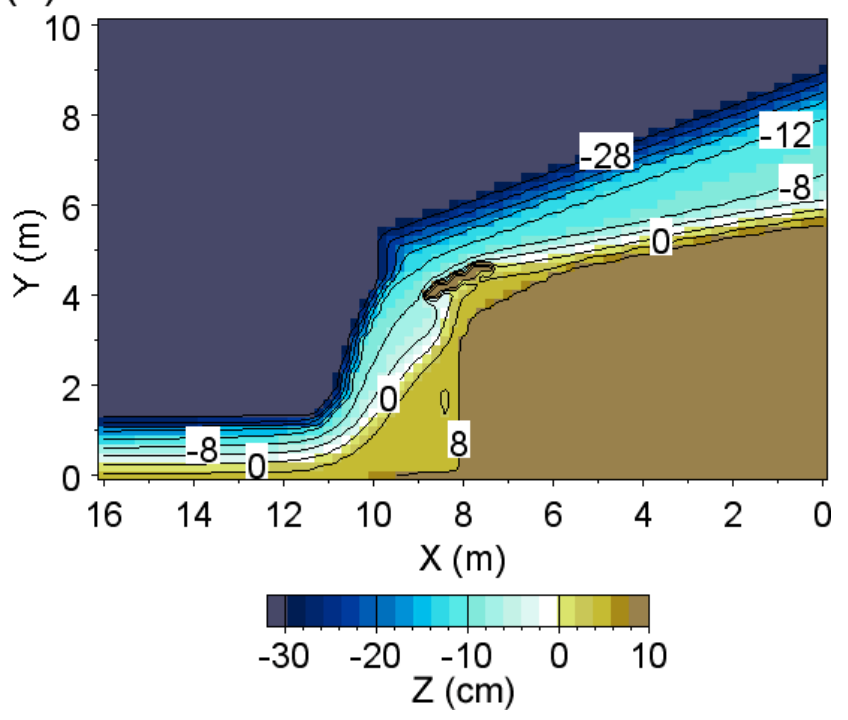

Figure 7. Predicted topographic changes around a detached breakwater placed on a steep coast with a large shoreline curvature. 


\section{Comparison between effects of groin and detached breakwater}

Figure 8 shows the bathymetric changes from the initial bathymetry in the case of a natural sandy beach and in the cases with a groin and a detached breakwater. With no structures, severe beach

(a) No structure

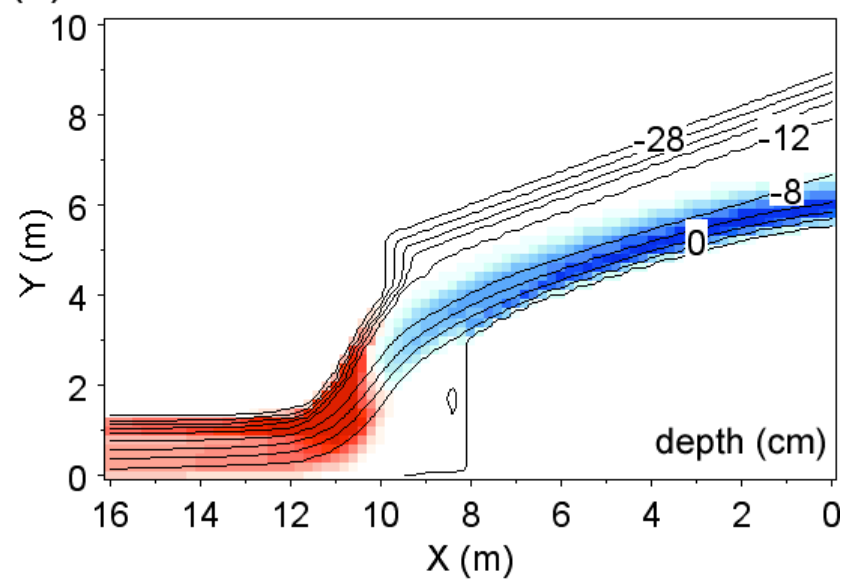

(b) Groin

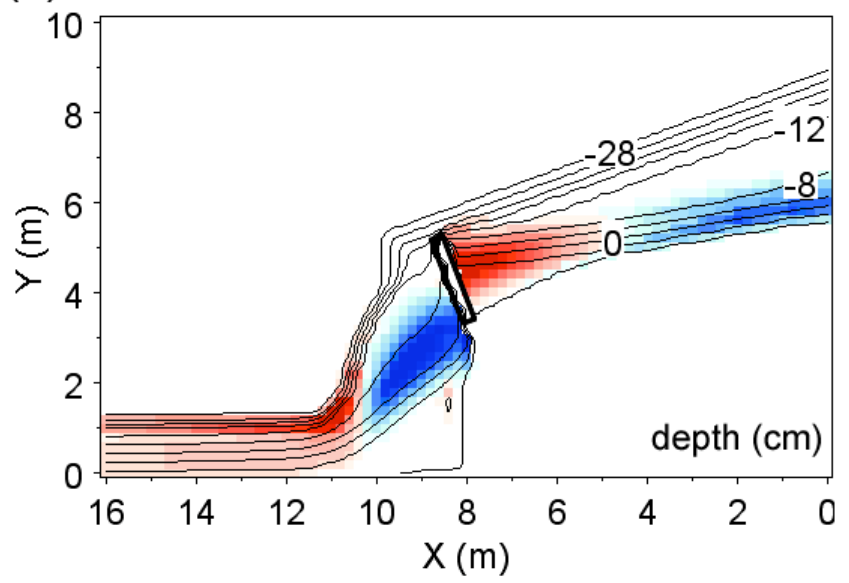

(c) Detached breakwater

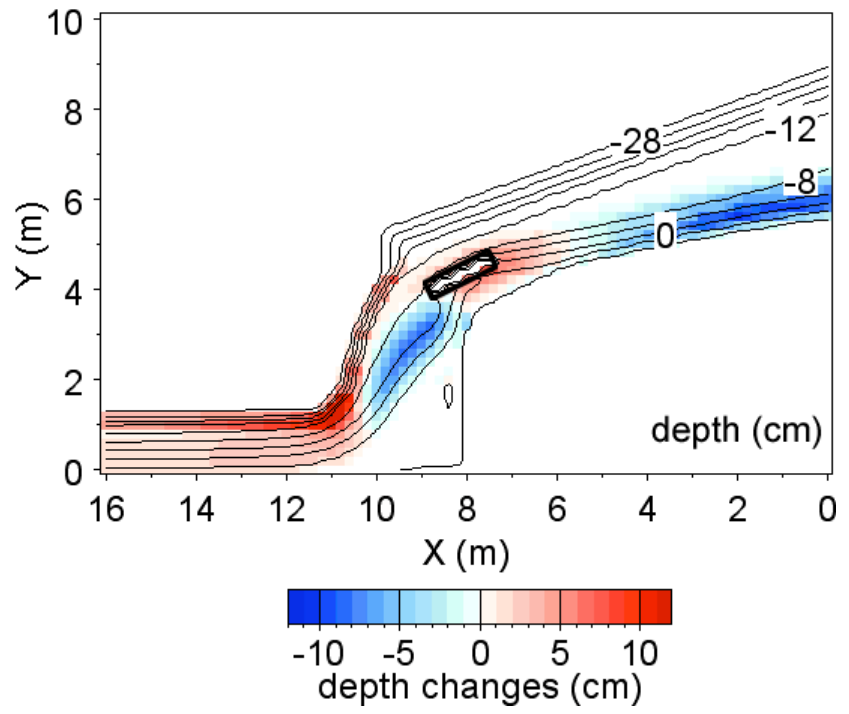

Figure 8. Bathymetric changes in case of natural sandy beach, and in the cases with a groin and a detached breakwater relative to initial topography. 
erosion occurred in a zone at $X \leq 8 \mathrm{~m}$, and eroded sand was transported leftward, resulting in sand deposition where there is a large shoreline curvature (Fig. 8(a)). With a groin, sand was mainly deposited upcoast of the groin, and a stable shoreline was formed owing to the blockage of leftward longshore sand transport by the groin, and the extent of erosion near the end of the area upcoast of the groin was reduced. In contrast, beach erosion immediately downcoast of the groin was intensified, whereas sand deposition near $X=11 \mathrm{~m}$ was suppressed because of the decrease in sand supply from the region upcoast (Fig. 8(b)).

With the detached breakwater, although sand was deposited upcoast of the detached breakwater and erosion occurred downcoast, beach changes were minimized compared with that in the case with a groin, because part of the longshore transport was able to pass through the zone shoreward and offshore zones of the detached breakwater (Fig. 8(c)). Sand can be deposited immediately offshore of the detached breakwater, causing the passage of part of the longshore transport. Thus, the construction of a detached breakwater causes beach changes milder than that in the case with a groin.

Figures 9(a) and 9(b) show the difference in the bathymetry between the cases in which a groin and a detached breakwater was installed relative to that without any measure, respectively. In the case with a groin, symmetrical bathymetric changes were observed with respect to the groin: sand deposition upcoast and erosion downcoast of the groin. In the case with a detached breakwater, although sand was deposited upcoast of the detached breakwater and erosion occurred downcoast, sand was also deposited offshore of the detached breakwater because some of the littoral sand passed offshore of the detached breakwater.

(a) Groin - No structure

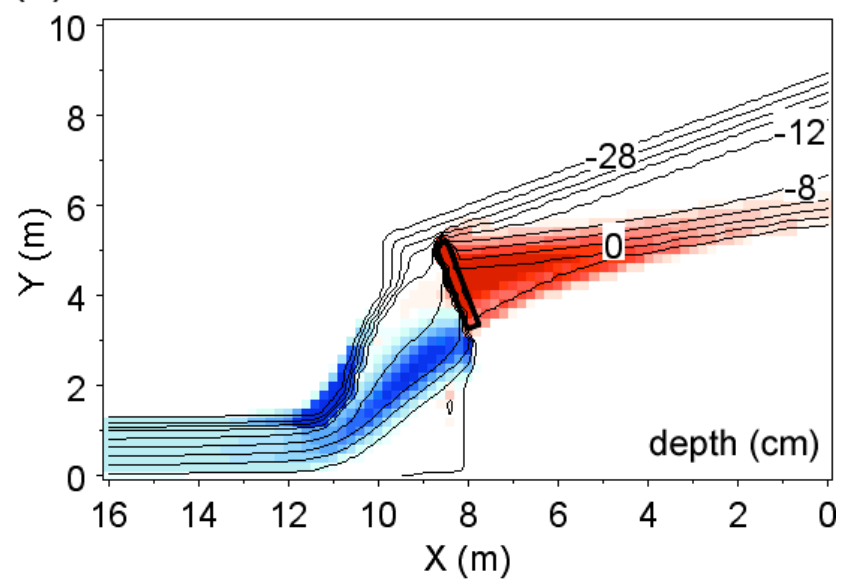

(b) Detached breakwater - No structure

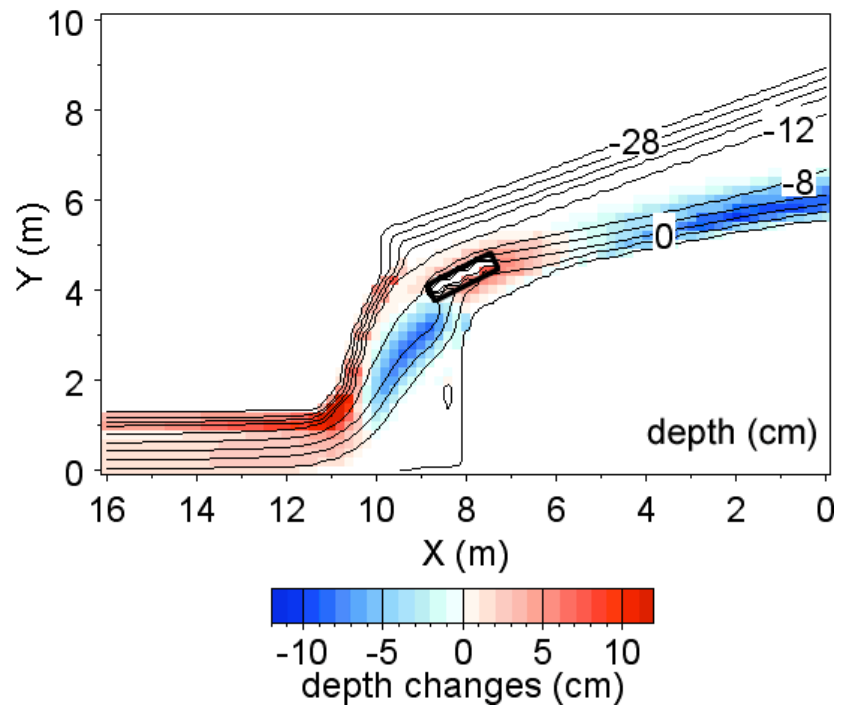

Figure 9. Comparison of cases of a groin and detached breakwater relative to that with no structure. 
Along the curved shoreline, leftward longshore sand transport continuously develops, and the shoreline is in dynamic equilibrium. This is the fundamental difference from case of the shoreline under static equilibrium. If a structure blocking this longshore sand transport is constructed, marked beach erosion will occur. Furthermore, on the updrift side of a groin, offshore sand loss may occur, because the beach slope increases owing to the gradual sand deposition on the offshore seabed. For example, owing to the calculation results along transect A-A', as shown in Fig. 6(a), the beach slope near the area of a $10 \mathrm{~cm}$ depth was $1 / 20$ under the initial condition, and a uniformly steep slope as steep as $1 / 5$ connected to the shoreline was formed after $4 \mathrm{hr}$, enhancing the possibility of offshore sand movement. Considering that the equilibrium slope of sand depends on sand grain size and increases with the grain size of sand, fine materials are easily carried off into the deep sea through the steep slope along transect A-A' upcoast of the groin, as shown in Fig. 6(a), because the beach slope became steeper to lose the stability of fine materials. In fact, the erosion and loss of fine sand on the basis of this mechanism was observed downcoast of L-shaped groin on the Shimizu coast (San-nami et al., 2012).

\section{CONCLUSION}

The BG model proposed by Serizawa and Uda (2011) was used for predicting beach changes around a groin and a detached breakwater placed on a steep coast with a large shoreline curvature. The results of a movable bed experiment by Uda et al. were confirmed using the BG model. The differences between the effects of a groin and a detached breakwater in controlling longshore sand transport on a steep coast were successfully explained. Using the BG model, solutions can be stably obtained with a small calculation load, which shows the effectiveness of the BG model in predicting beach changes.

\section{REFERENCES}

Dally, W. R., R. G. Dean, and R. A. Dalrymple. 1984. A model for breaker decay on beaches, Proc. 19th ICCE, 82-97.

Goda, Y. 1985. Random Seas and Design of Maritime Structures. University of Tokyo Press, Tokyo, $323 \mathrm{p}$.

Mase, H. 2001. Multidirectional random wave transformation model based on energy balance equation, Coastal Eng. J., JSCE, 43(4), 317-337.

Ozasa, H., and A. H. Brampton. 1980. Model for predicting the shoreline evolution of beaches backed by seawalls, Coastal Eng., 4, 47-64.

San-nami, T., T. Uda, N. Ohashi, H. Iwamoto, M. Serizawa, T. Ishikawa, and S. Miyahara. 2012. Prediction of beach erosion caused by reduction of fluvial sand supply due to excess sand mining and beach recovery after mining prohibition, Proc. 33rd ICCE. (in press)

Serizawa, M., and T. Uda. 2011. Prediction of formation of sand spit on coast with sudden change using improved BG model, Coastal Sediments '11, 1907-1919.

Uda, T., K. Yamamoto, K. Saguchi, and K. Kataoka. 1992. Experimental study on stabilization of a sand spit, Annu. J. Coastal Eng., JSCE, Vol. 39, 466-470. (in Japanese)

Yamada, K., T. Uda, Y. Suwa, and T. San-nami. 2010. Mechanism of offshore sand discharge into submarine canyon triggered by construction of detached breakwater close to shoreline, Proc. 32nd ICCE, sediment. 18, 1-11. 